\section{Recurrent rectovaginal fistula: treatment with self-expanding metal stents}

Postoperative rectovaginal fistula is a rare complication after colorectal resection for cancer. This adverse event results in a scenario of fear and misunderstanding for the patient [1-6]. Often, local inflammation, widespread infection, friability of the vaginal and rectal tissue, and the inevitably reduced perfusion of blood to the lower end of the rectum make any form of treatment hazardous and likely to cause complications. Even in cases in which the fistula heals, altered colorectal motility is common.

Self-expandable metal stents can be used to treat patients with rectovaginal fistula after colorectal resection for cancer. Of 10 patients who had rectovaginal fistula after colorectal resection for cancer and were treated with endoscopic placement of a self-expandable metal stent, three had been referred after multiple failed operations. All three patients had a diverting proximal stoma. We used fully covered colonic stents $10 \mathrm{~cm}$ in length and $28 \mathrm{~mm}$ in diameter (Tae Woong Medical, Gimpo $\mathrm{Si}$, Gyeonggi-do, South Korea) in all of them. There were no complications after the procedures. In one patient, the rectovaginal fistula healed without evidence of major fecal incontinence 8 months after stent insertion ( $\bullet$ Fig.1a-f). In the remaining two patients, the fistula decreased significantly in size (from $4 \times 4 \mathrm{~cm}$ to $1 \times 1 \mathrm{~cm}$ ) without evidence of local tissue inflammation; both of these patients underwent a successful flap transposition 8 months after stent placement. In all three patients, the stent dislodged 3 months after placement, and a new stent was placed.

Self-expandable metal stents are a valid adjunct to the treatment of patients with complex, recurrent rectovaginal fistula after colorectal resection for cancer.
Endoscopy_UCTN_Code_TTT_1AQ_2AG

Competing interests: None

\section{Antonietta Lamazza ${ }^{1}$, Enrico Fiori ${ }^{1}$, Alberto Schillaci ${ }^{1}$, Antonio V. Sterpetti ${ }^{1}$, Emanuele Lezoche ${ }^{2}$}

${ }^{1}$ University of Rome La Sapienza, Department of Surgery, Istituto Pietro Valdoni, Rome, Italy

${ }^{2}$ University of Rome, Department of General Surgery, Surgical Specialties and Organ Transplantation Paride Stefanini, Rome, Italy

\section{References}

1 Ommer A, Herold A, Berg E et al. German S3guideline: rectovaginal fistula. Ger Med Sci 2013; 10: 15

2 Schloricke E, Zimmermann M, Hoffmann M et al. Surgical treatment and prognosis of rectovaginal fistulae according to their origin. Zentralbl Chir 2012; 137: 390-395

3 Auyang ED, Santos BF, Enter DH et al. Natural orifice tranlumenal endoscopic surgery: a technical review. Surg Endosc 2011; 25: $3135-3148$

4 Jarrar A, Church J. Advancement flap repair: a good option for complex anorectal fistulas. Dis Colon Rectum 2011; 54: 1537-1541
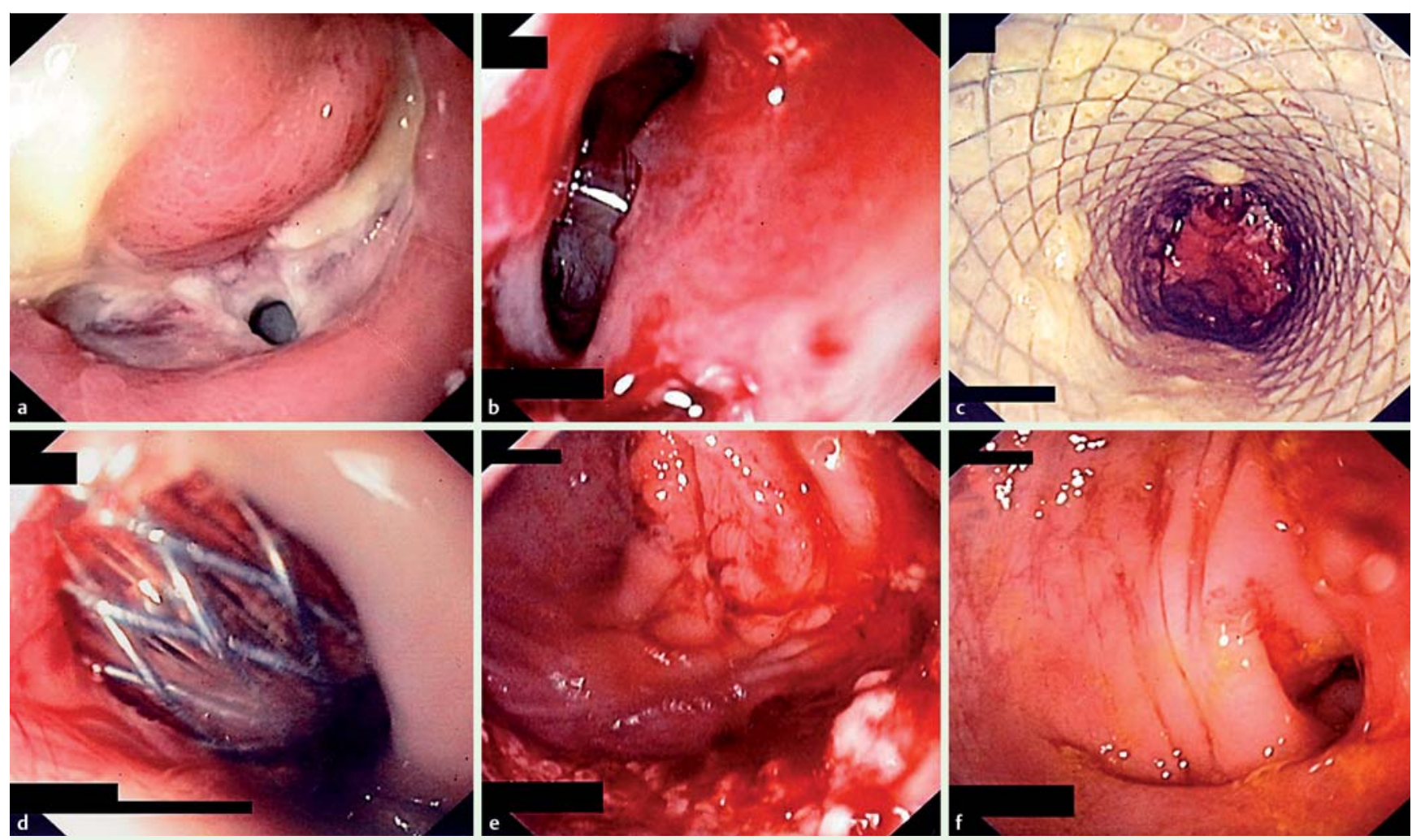

Fig. 1 Recurrent rectovaginal fistula. a View from the rectal lumen. b Same patient; view from the vaginal lumen. $\mathbf{c}$ Insertion of a self-expanding metal stent. View from the rectal lumen. $\mathbf{d}$ Insertion of a self-expanding metal stent. View from the vaginal wall. e Complete healing of the fistula. There is still some inflammation immediately after removal of the stent. $\mathbf{f}$ Resolution of the inflammation 2 weeks after stent removal. 
5 Zimmermann MS, Hoffmann M, Hildebrand $P$ et al. Surgical repair of rectovaginal fistulas: a challenge. Int J Colorectal Dis 2011; 26: 817-819

6 Machado GR, Bojalian MO, Reeves ME. Transanal endoscopic repair of rectal anastomotic defects. Arch Surg 2005; 140: 1219-1222
Bibliography

Dol http://dx.doi.org/

10.1055/s-0034-1377497

Endoscopy 2015; 47: E149-E150

(C) Georg Thieme Verlag KG

Stuttgart · New York

ISSN 0013-726X
Corresponding author

Antonio V. Sterpetti, MD

Istituto Pietro Valdoni

Viale del Policlinico

00167 Rome

Italy

Fax: +39-6-49972245

antonio.sterpetti@uniroma1.it 